\title{
Six minute walk distance is a predictor of survival in patients with chronic obstructive pulmonary disease undergoing pulmonary rehabilitation
}

\author{
Esther Dajczman RN MScA ${ }^{1,2,3}$, Rima Wardini MSc ${ }^{1}$, Goulnar Kasymjanova MD², David Préfontaine PhD ${ }^{1,3}$ \\ Marc Alexander Baltzan MD FRCP1,3, Norman Wolkove MD FRCP1,2,3
}

E Dajczman, R Wardini, G Kasymjanova, D Préfontaine, MA Baltzan, $\mathrm{N}$ Wolkove. Six minute walk distance is a predictor of survival in patients with chronic obstructive pulmonary disease undergoing pulmonary rehabilitation. Can Respir J 2015;22(4):225-229.

BACKGROUND: Chronic obstructive pulmonary disease (COPD) is a progressive and distressing disease with a trajectory that is often difficult to predict.

OBJECTIVE: To determine whether initial 6 min walk distance (6MWD) or change in $6 \mathrm{MWD}$ following inpatient pulmonary rehabilitation (PR) predicted survival.

METHODS: Patients referred for PR in 2010 were studied in a retrospective chart review. Measures of 6MWD before and following PR were recorded. Initial 6MWD was categorized as $\geq 250 \mathrm{~m}, 150 \mathrm{~m}$ to $249 \mathrm{~m}$ and $\leq 149 \mathrm{~m}$. Government databases provided survival status up until December 2013 and survival analyses were performed. Initial 6MWD and a minimally important difference (MID) of $\geq 30 \mathrm{~m}$ were used for survival analysis.

RESULTS: The cohort consisted of 237 patients ( 92 men, 145 women) with severe COPD. Mean $( \pm \mathrm{SD})$ forced expiratory volume in $1 \mathrm{~s}\left(\mathrm{FEV}_{1}\right)$ was $0.75 \pm 0.36 \mathrm{~L}$, with a mean $\mathrm{FEV}_{1} /$ forced vital capacity (FVC) ratio of $0.57 \pm 0.16$. Overall three-year survival was $58 \%$. Mean survival for the study period as per predefined categories of 6MWD of $\geq 250 \mathrm{~m}, 150 \mathrm{~m}$ to $249 \mathrm{~m}$ and $\leq 149 \mathrm{~m}$ was $42.2,37.0$ and 27.8 months ( $\mathrm{P}<0.001$ ), respectively, with a three-year survival of $81 \%, 66 \%$ and $34 \%$ observed, respectively. Overall mean change in $6 \mathrm{MWD}$ was $62 \pm 57 \mathrm{~m}$, and a minimal improvement of $\geq 30 \mathrm{~m}$ was observed in $72 \%$ of patients. In the lowest walking group, early mortality was significantly higher among those who did not achieve minimal improvement. Older age, male sex and shorter initial 6MWD were negative predictors of survival.

CONCLUSION: In patients with severe COPD, initial 6MWD was predictive of survival. Overall survival at three years was only $58 \%$ and was especially poor $(34 \%)$ in patients with low $(<150 \mathrm{~m})$ initial walk distance.

Key Words: 6MWD; COPD; Pulmonary rehabilitation; Mortality

Cingo hronic obstructive pulmonary disease (COPD) is the third leading cause of death worldwide, and its prevalence and consequent mortality is expected to increase in the coming decades $(1,2)$. The morbidity associated with COPD is significant and accounts for one of the most common reasons for hospitalization in Canada (3). Patients with COPD cope with progressive symptoms that are both distressing and debilitating. The trajectory of disease and, in particular, mortality, is often difficult to predict (4). Exercise testing and composite indexes, such as the BODE index, have been used to predict mortality, but can be time consuming to collect and are, therefore, often not utilized clinically (5-7)

The use of the 6 min walk test (6MWT) as a clinical tool to assess patients with COPD is of interest $(8,9)$. The $6 \mathrm{MWT}$ is used to evaluate exercise capacity. It is simple to perform and correlates well with more sophisticated tests requiring a treadmill or cycle ergometer $(8,10)$. As such, the distance walked in 6 min $(6 \mathrm{MWD})$ is frequently used as an outcome measure in evaluating the benefit of pulmonary rehabilitation (PR) (11-13). The 6MWT has also been used as a single
Le test de marche de six minutes est un indicateur de survie chez les patients atteints d'une maladie pulmonaire obstructive chronique qui sont en réadaptation pulmonaire

HISTORIQUE : La maladie pulmonaire obstructive chronique (MPOC) une maladie évolutive et pénible, à la trajectoire souvent difficile à prévoir. OBJECTIF : Déterminer si le test de marche de six minutes (TMSM) initial ou un changement au TMSM après la réadaptation pulmonaire (RP) des patients hospitalisés sont indicateurs de la survie.

MÉTHODOLOGIE : Les chercheurs ont procédé à l'analyse rétrospective des dossiers des patients orientés vers une RP en 2010. Les chercheurs ont mesuré le TMSM avant et après la RP. Le TMSM était classé à plus de $250 \mathrm{~m}$, entre $150 \mathrm{~m}$ et $249 \mathrm{~m}$ et à moins de $149 \mathrm{~m}$. Les bases de données gouvernementales ont fourni le statut de survie jusqu'en décembre 2013, et les chercheurs ont effectué les analyses de survie. Un TMSM initial à l'importance d'amplitude minimale (IAM) de plus de $30 \mathrm{~m}$ était été utilisé pour l'analyse de survie.

RÉSULTATS : La cohorte était composée de 237 patients (92 hommes, 145 femmes) atteints d'une grave MPOC. Le volume expiratoire maximal par seconde (VEMS) moyen ( \pm ÉT) était de $0,75 \pm 0,36 \mathrm{~L}$, pour un ratio entre le

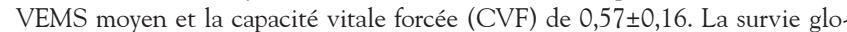
bale au bout de trois ans s'élevait à $58 \%$. La survie moyenne pendant la période de l'étude, conformément aux catégories prédéfinies de TMSM d'au moins $250 \mathrm{~m}$, de $150 \mathrm{~m}$ à $249 \mathrm{~m}$ et de $149 \mathrm{~m}$ ou moins étaient de 42,2 mois, de 37,0 mois et de 27,8 mois $(P<0,001)$, respectivement, pour une survie de $81 \%$, de $66 \%$ et de $34 \%$ au bout de trois ans, respectivement. Le changement global moyen du TMSM était de $62 \pm 57 \mathrm{~m}$, et les chercheurs ont observé une amélioration minimale d'au moins $30 \mathrm{~m}$ chez $72 \%$ des patients. Dans le groupe qui franchissait la plus courte distance, la mortalité précoce était considérablement plus élevée chez ceux qui n'obtenaient pas une amélioration minimale. Un âge plus avancé, le sexe masculin et un TMSM initial plus court étaient des indicateurs de survie négatifs.

CONCLUSION : Chez les patients atteints d'une grave MOPD, le TMSM initial était indicateur de survie. La survie globale au bout de trois ans n'atteignait que $58 \%$ et était particulièrement basse (34\%) chez les patients dont la distance de marche initiale était faible (moins de $150 \mathrm{~m}$ ).

measure of functional status in COPD, but is not commonly used as an individual parameter to help predict mortality in patients with this disease (11). Despite its increased utilization in patients with moderate to severe COPD, we believed that further study was necessary to determine its usefulness and predictive power. Specifically, our goal was to determine whether the initial 6MWD or change in 6MWD following $\mathrm{PR}$ was a predictor of survival in patients with severe COPD.

Inpatient PR program

\section{METHODS}

Patients referred to the authors' centre are typically those admitted following an acute exacerbation, or due to progressive decline from their disease. In addition to medical management, extensive patient education and psychosocial support, the PR program at Mount Sinai Hospital (MSH, Montreal, Quebec) includes exercise sessions given five times per week for three weeks. These sessions consist of endurance and resistance training, and are supervised by physiotherapists. Patients are able to perform their endurance training on either a treadmill or cycle

\footnotetext{
${ }^{1}$ Mount Sinai Hospital Centre; ${ }^{2}$ Jewish General Hospital; ${ }^{3}$ McGill University, Montreal, Quebec

Correspondence and reprints: Dr Marc Alexander Baltzan, 5690 Cavendish Boulevard Montreal, Quebec H4W 1S7.

Telephone 514-369-2222, fax 514-369-2225, e-mail marc.baltzan@mcgill.ca
} 
TABLE 1

Demographics and clinical characteristics according to categories of 6 min walk distance (6MWD)

\begin{tabular}{|c|c|c|c|c|}
\hline \multirow[b]{2}{*}{ Characteristic } & \multicolumn{3}{|c|}{ 6MWD, m } & \multirow[b]{2}{*}{$\mathbf{P}$} \\
\hline & $\geq 250$ & $150-249$ & $\leq 149$ & \\
\hline$n(\%)$ & $57(24)$ & $98(41)$ & $82(35)$ & - \\
\hline Sex, male/female, $n / n$ & $24 / 33$ & $44 / 54$ & $24 / 58$ & $<0.085$ \\
\hline Age, years & $68 \pm 8.6$ & $68 \pm 8.9$ & $71 \pm 8.7^{*}$ & 0.039 \\
\hline $\mathrm{FEV}_{1}, \mathrm{~L}$ & $0.91 \pm 0.46^{*}$ & $0.69 \pm 0.28$ & $0.70 \pm 0.34$ & $<0.001$ \\
\hline $\mathrm{FEV}_{1}, \%$ predicted & $39.3 \pm 19.9^{*}$ & $30.6 \pm 13.0$ & $32.2 \pm 14.7$ & 0.003 \\
\hline FVC, L & $1.62 \pm 0.70^{*}$ & $1.28 \pm 0.45$ & $1.17 \pm 0.41$ & $<0.001$ \\
\hline $\mathrm{FEV}_{1} / \mathrm{FVC}$ & $56.5 \pm 14.7$ & $56.2 \pm 17.1$ & $59.1 \pm 16.8$ & 0.491 \\
\hline Comorbidities ( $\geq 4)$, & $45(80)$ & $84(87)$ & $73(94)$ & 0.070 \\
\hline
\end{tabular}

$\mathrm{n}(\%)$

\begin{tabular}{lcccc} 
6MWD at admission, $m$ & $307.8 \pm 46.0$ & $202.0 \pm 29.7$ & $88.9 \pm 37.3$ & - \\
6MWD at discharge, $m$ & $344.5 \pm 64.5$ & $261.9 \pm 52.1$ & $174.1 \pm 73.5$ & $<0.001$ \\
Change in 6MWD, $m$ & $36.7 \pm 51.1$ & $57.6 \pm 49.3$ & $84.9 \pm 61.2$ & $<0.001$ \\
$\begin{array}{c}\text { Patients attaining MID, } \\
\text { n (\%) }\end{array}$ & $35(61)$ & $71(72)$ & $65(79)$ & 0.69 \\
\hline
\end{tabular}

Data presented as mean $\pm S D$ unless otherwise indicated. One-way ANOVA followed by Bonferroni's method for multiple comparisons when necessary. *Indicates that the value in this group is significantly different from the other two groups. FEV 1 Forced expiratory volume in 1 s; FVC Forced vital capacity; MID Minimally important difference

ergometer. Strength training of upper and lower extremities is accomplished using free weights and body resistance. The aim is for patients to progress throughout their PR program with a primary clinical goal of improving their overall symptoms and functional capacity. This is assessed, in part, by determining whether they have achieved a minimally important difference (MID) in 6MWD of $\geq 30 \mathrm{~m}(12,13)$ while reducing dyspnea.

\section{Participants}

The present study included patients identified using a retrospective chart review protocol. A cohort with a primary diagnosis of COPD admitted for PR on the respiratory ward of MSH from January 1, 2010 to December 31, 2010 was selected using the Logibec (Logibec Groupe Informatique, Canada) database system. All patients included in the present study had a documented diagnosis of COPD and were classified according to Global Initiative for Obstructive Lung Disease criteria (3). Patients in the present study were those who had been stable at the time of entry into PR. Individuals who failed to complete the PR program, as well as those lacking a pre- and/or post-PR 6MWD evaluation, were excluded. The present study was approved by the MSH Research Ethics Committee.

\section{Data collection and clinical outcomes}

Patient charts were reviewed for demographic information including age, sex, body mass index (BMI) and smoking history. Measures of lung function (forced expiratory volume in $1 \mathrm{~s}\left[\mathrm{FEV}_{1}\right], \mathrm{FEV}_{1} \%$ predicted, $\mathrm{FEV}_{1}$ (forced vital capacity ratio), as well as initial 6MWD and 6MWD following PR were recorded. Similar to the categories used in the BODE index, the initial 6MWD in the present study was divided into tertiles rather than quartiles for simplicity purposes (5). The initial 6MWD categories of $\geq 250 \mathrm{~m}, 150 \mathrm{~m}$ to $249 \mathrm{~m}$ and $\leq 149 \mathrm{~m}$ corresponded to high, medium and low walkers, respectively. Comorbid conditions were extracted from the medical charts and were classified according to International Classification of Diseases, 10th Revision (ICD 10) criteria (14). Survival status was ascertained using government databases including vital statistics and the universal health care data of the Régie de l'assurance maladie du Québec for the cohort up until December 15, 2013.
Measure of functional status

The 6MWT is a self-paced protocol that permits patients to choose their own walking pace intensity and allows them to stop and rest during the test. The total distance walked is recorded as the 6MWD. This test was performed as per American Thoracic Society standards (11) as part of the physiotherapy assessment at admission and before discharge from the PR program.

\section{Statistical analyses}

Demographic and clinical data are summarized using means, SDs and medians for continuous variables, and expressed in percentages for categorical variables. Clinical outcomes are presented as the proportion of patients experiencing outcomes of interest (categories of 6MWD and MID). Differences in mean values for descriptive variables in each of the three 6MWD categories were analyzed using a one-way ANOVA. If an overall difference was significant according to ANOVA, post hoc analyses using the Bonferroni method were performed. The starting point for survival was date of admission to hospital. In cases in which there were multiple admissions in the same year, only the first admission was used. Mortality data were obtained from government databases up until December 15, 2013, and survival was censored as of this date. Censoring time was fixed at December 15, 2013 , for a potential maximum follow-up time of 47.5 months and patients who were alive at this date were considered to be censored. Survival was evaluated descriptively using Kaplan-Meier methods for censored data $(15,16)$.

An exploratory analysis was conducted to identify the prognostic factors for survival. The log-rank statistic was used to make nonparametric comparisons using the Kaplan-Meier as well as Cox proportional hazard methods. The following baseline confounding variables were used for Cox regression: age, sex, comorbidity, $\mathrm{FEV}_{1}$ and initial 6MWD. As an exploratory analysis, demographic and clinical data were presented separately for three groups of 6MWD, and differences in key characteristics between the groups were investigated. Within the three categories of admission 6MWD, statistical significance was accepted at $\mathrm{P} \leq 0.05$. Statistical analyses were conducted using SPSS version 20 (IBM Corporation, USA).

\section{RESULTS}

The medical charts of 282 patients admitted and considered for PR were reviewed and, of these, 45 were excluded from the analysis due to missing values for either or both pre- and post-6MWD. Therefore, 237 patients with severe COPD comprised the final cohort.

The mean $( \pm$ SD) age of the study group was $69 \pm 8.8$ years and women outnumbered men ( 145 women, 92 men). The mean $\mathrm{FEV}_{1}$ of $0.75 \pm 0.36 \mathrm{~L}$ indicated a population with severe airway obstruction. Forty percent of patients were transferred to PR from acute-care hospitals, while $60 \%$ were admitted from home. Multiple comorbidities were common in this patient cohort, with $85 \%$ (202 of 237) having $\geq 4$ comorbid conditions. More specifically, the most commonly occurring comorbid conditions as per ICD-10 classifications were: endocrine, nutritional and metabolic diseases (62\%), hypertension (50\%), diseases of the digestive system (44\%), coronary artery diseases (39\%), and anxiety and depression (39\%). The mean 6MWD at entry to PR was $188.3 \pm 91.1 \mathrm{~m}$. Following PR, the mean $6 \mathrm{MWD}$ was $251.4 \pm 90.4 \mathrm{~m}$, and the mean change in 6MWD was $62.0 \pm 57.0 \mathrm{~m}$. The MID of $\geq 30 \mathrm{~m}$ was observed in $72 \%$ (171 of 237 ) of patients.

Demographic and clinical characteristics according to 6MWD category are presented in Table 1. Patients in the low walking category were predominantly female and most had $\geq 4$ comorbid conditions. Patients in all three groups improved their 6MWD following PR. Those with the lowest initial 6MWD had the greatest relative improvement post-PR.

When conducting survival analysis, 90 deaths were observed. Patients excluded from study due to a missing 6MWD pre- or post-PR, had a similar overall survival as those included in the cohort $(\mathrm{P}=0.45)$. Mean overall survival for the observation period was 35.7 months $(95 \%$ 
TABLE 2

Percent survival per year for each walk distance category

\begin{tabular}{lccc}
\hline Walk distance category & 1 year & 2 years & 3 years \\
\hline$\geq 250 \mathrm{~m}$ & 91 & 88 & 81 \\
$150 \mathrm{~m}-249 \mathrm{~m}$ & 73 & 71 & 66 \\
$\leq 149 \mathrm{~m}$ & 55 & 45 & 34 \\
\hline
\end{tabular}

Data presented as \%

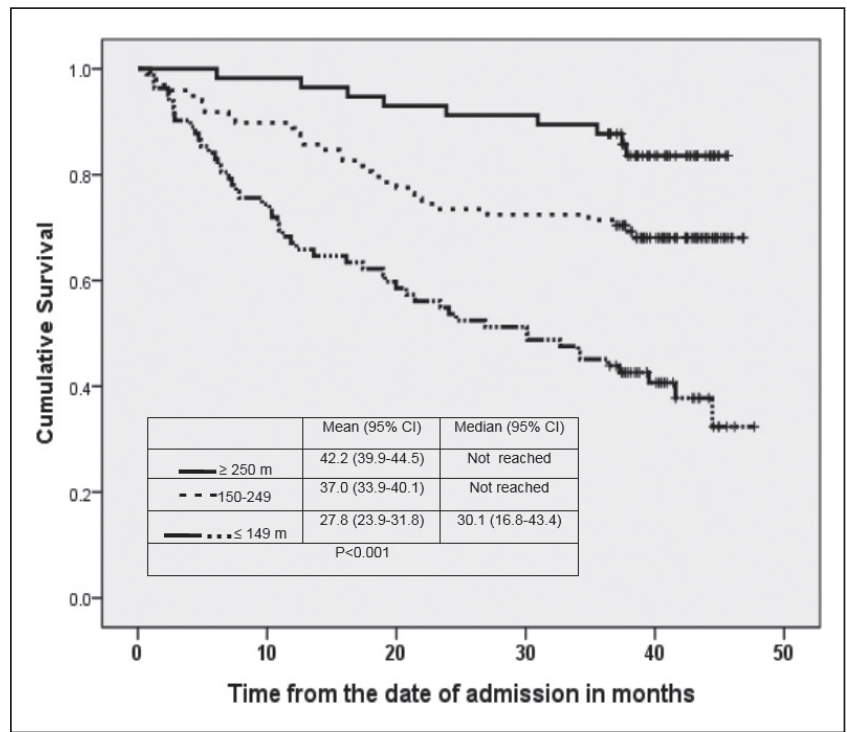

Figure 1) Survival curves according to categories of 6 min walk distance

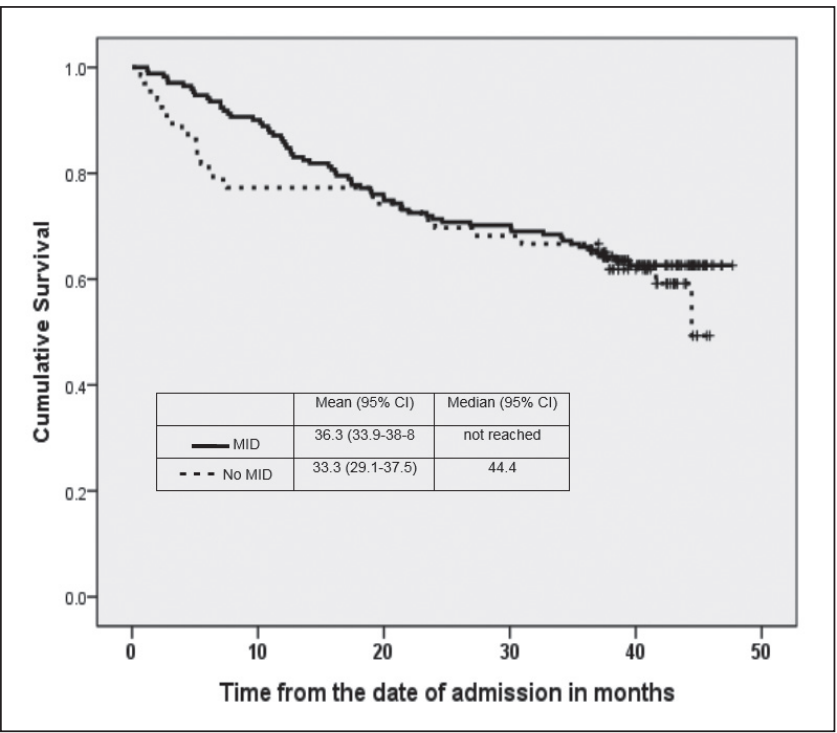

Figure 2) Survival according to achieving at least $30 \mathrm{~m}$ (minimally important difference [MID]) in 6 min walk distance (6MWD) after pulmonary rehabilitation. There is no difference in survival between those who did and those who did not achieve a change of at least $30 \mathrm{~m}$ in $6 \mathrm{MWD}$

CI 33.6 to 37.9 months), with a one-, two- and three-year survival of $71 \%, 66 \%$ and $58 \%$, respectively. The median survival had not yet been reached. Mean survival for the study period in different walking categories was 42.2 months (95\% CI 39.9 to 44.5 months) for high walkers, 37.0 months (95\% CI 33.9 to 40.1 months) for medium walkers and 27.8 months (95\% CI 23.9 to 31.8 months) for low walkers $(\mathrm{P}<0.001)$. One, two- and three-year survival for each walking category are presented in Table 2. As shown, survival in the lowest walking category was $55 \%$ at one year and only $34 \%$ at three years. This is illustrated

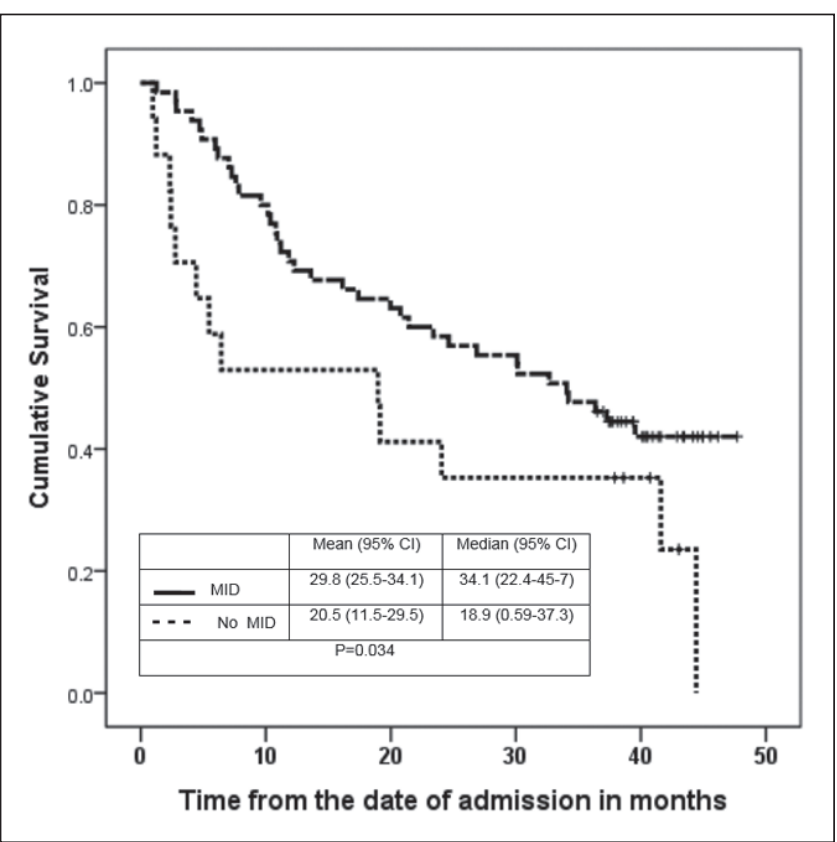

Figure 3) Survival according to minimally important difference (MID) in the low walking group. Survival was significantly greater in patients who improved by at least $30 \mathrm{~m}$ (ie, MID) post pulmonary rehabilitation compared with those who did not achieve an MID

\section{TABLE 3}

\section{Cox proportional hazard model}

\begin{tabular}{lcr}
\hline Variable in the equation & HR $(\mathbf{9 5} \% \mathrm{Cl})$ & \multicolumn{1}{c}{$\mathbf{P}$} \\
\hline Age & $1.049(1.023-1.075)$ & $<0.001$ \\
Sex & $0.623(0.400-0.970)$ & 0.036 \\
Initial 6 min walk distance & $0.995(0.992-0.997)$ & $<0.001$ \\
Forced expiratory volume in 1 s & $0.521(0.261-1.039)$ & 0.064 \\
\hline
\end{tabular}

${ }^{*}$ Categorical variable (female sex decreased the probablity of death by $38 \%$ )

graphically in a Kaplan-Meier survival curve in Figure 1. When analyzed for only the first year, an initial survival benefit was observed in patients who attained an MID ( $\geq 30 \mathrm{~m}$ ) in 6MWD; however, no significant difference in overall survival was detected when all survival data were analyzed (Figure 2). There was no survival difference between patients who reached an MID versus those who did not in the high walking $(\geq 250 \mathrm{~m})$ and medium walking ( $150 \mathrm{~m}$ to $249 \mathrm{~m}$ ) groups. However, for those in the lowest walking category $(\leq 149 \mathrm{~m})$, a significant difference in median survival was observed for those who achieved an MID with $P R(P=0.034)$. In those in the lowest walking category, median survival for the study period was 34.1 months (95\% CI 22.47 to 45.7 months) in those who attained an MID (65 of 82 patients) compared with 18.9 months (95\% CI 0.6 to 37.3 months) in those who did not reach an MID (17 of 82 patients) (Figure 3). This corresponded to a three-year survival of $39 \%$ in those who achieved an MID versus 18\% in those who did not.

The final multivariate Cox proportional hazard model is presented in Table 3. From the variables included in the model, only age, sex and initial 6MWD were predictive of survival. Results demonstrate that the probability of death increased by $4 \%$ for every additional year of life (ie, increasing age) while adjusting for other variables (sex, initial 6MWD and $\mathrm{FEV}_{1}$ ). In models with the same covariates, female sex decreased the probability of death by $38 \%$ (HR 0.62 [95\% CI 0.40 to 0.97]) and for every additional metre attained during the 6MWD at admission the likelihood of death decreased by $1 \%$. However, the number of comorbid conditions and lung function ( $\mathrm{FEV}_{1} \%$ predicted) were not predictive of survival in the present cohort. 


\section{DISCUSSION}

The present chart review of patients with severe COPD and significant comorbidity attending an inpatient PR program revealed that initial 6MWD was predictive of survival. Overall survival at three years was only $58 \%$, and was particularly poor in patients with a low $(<150 \mathrm{~m})$ initial walk distance $(34 \%)$. Although the majority of patients achieved a minimally important improvement in 6MWD following PR (an important outcome for efficacy of the program), this was not predictive of survival. However, this was predictive of mortality in the subgroup with the lowest 6MWD whose survival in those who failed to achieve an MID was only $18 \%$ at three years. The Cox regression proportional hazards model used to identify factors associated with survival was important in further defining risk in this COPD population. In the current study, older age, male sex and shorter initial 6MWD were negative predictors of survival.

The 6MWT is a standardized, reliable and practical measure that can be used in the clinical setting to assess functional capacity $(9,17)$. This inexpensive, minimally invasive test is reflective of activities of daily living (11), and has been used to characterize disease severity and assess patient progress before and after clinical interventions such as PR $(7,10)$. Of importance, a low 6MWD has been associated with mortality in a variety of pulmonary settings (18-20). The 6MWD has also been used along with measures of lung function, BMI and dyspnea to calculate the BODE index (5). Our study has shown that determination of the 6MWD alone may provide a simpler way to predict mortality in patients with COPD.

There have been previous attempts to predict survival in COPD. Studies have shown that exercise capacity is a better predictor of mortality than other measures such as $\mathrm{FEV}_{1}$ and BMI $(4,9)$. A review conducted by Celli (4), investigating predictors of mortality in COPD, stated that exercise capacity is the most important predictor of survival. Waschki et al (21) found that physical activity was the strongest predictor of all-cause mortality in patients with COPD. In that study, physical activity was measured by the use of a multisensory arm band to record activity. However, the 6MWD, a simpler measure, was also found to be predictive of mortality. Pinto-Plata et al (9) showed that 6MWD was able to predict survival in COPD patients and that patients unable to walk $>100 \mathrm{~m}$ had an extremely high mortality $(92 \%)$ at one year. Similarly, our study revealed high mortality in those with severe COPD, with an overall survival of only $58 \%$ at three years; however, our study is unique in that we have been able to further categorize survival on the basis of exercise capacity as measured by the 6MWD and response to PR.

Other authors have studied predictors of mortality in the PR setting in which the 6MWD is commonly utilized. Similar to our retrospective chart review, Enfield et al (22) performed a retrospective study involving $>800$ patients with end-stage COPD undergoing inpatient PR.These authors found that post-PR 6MWD was predictive of survival but initial 6MWD was not. An association between change in 6MWD and survival was also noted. The authors believed that while the initial 6MWD was the most important assessment, it was also the most confounding because many patients were recovering from a recent COPD exacerbation. Our study demonstrated that initial 6MWD was predictive of survival, and that 6MWD improved significantly with PR in patients with severe COPD. In contrast to the findings of Enfield et al (22), an association between change in $6 \mathrm{MWD}$ and survival was not evident for the group as a whole, but found only in the subgroup with the poorest exercise capacity. Differences in results may, in part, be related to the cohorts studied. Classification of disease in the study by Enfield et al (22) was based on the presence of comorbid illness, recent exacerbation and need for inpatient PR. Although, the present study also included patients with significant comorbidity, an important difference is that they were referred for PR from a variety of sources. This included acute care hospitals, community nursing services and outpatient clinics. Many patients had been admitted from home rather than hospital (60\% versus 40\%). Furthermore, not all patients were immediately recovering from an acute exacerbation, nor were they determined to be end stage as in the study by Enfield et al (22). Our study population had been referred from a large metropolitan region, and those in this cohort are typical of the more severe patients seen in most Canadian PR programs.

Previous studies have shown that change in 6MWD following PR is predictive of survival $(4,9,13)$. Despite the lack of a difference in survival for the group as a whole in our study, patients in the lowest walking group who had not achieved an MID had a significantly poorer survival compared with those who did. Although this finding is subject to the limitations of a subgroup analysis, the results are striking, warrant attention and require further confirmatory studies. This novel finding is indicative of a very high risk subgroup. Individuals with extremely limited exercise capacity and an inability to improve with an intensive PR program likely represent those with the greatest burden of disease who may be at or near the final stages of their illness.

The results of the present study are in agreement with previous findings in that patients with severe COPD and a low 6MWD have poor survival $(23,24)$. As such, patients with COPD and very limited exercise capacity as measured by the 6MWT must be considered to have reduced life expectancy, not unlike that of patients with various advanced carcinomas such as non-small cell lung cancer (25-27). Although the present study showed relatively high mortality in patients with severe COPD and poor functional status, it should be recognized that this was found despite aggressive treatment including PR. It is conceivable that mortality in similar patients not receiving PR could be even higher. This is relevant given the scarcity of resources and that the majority of patients with COPD do not participate in - or have access to - PR (28).

There were several limitations to the present study. First, this was a retrospective chart review with the inherent caveats of this methodology. As such, it was at times difficult to obtain precise information about patient comorbidity and medication use. Second, there were several patients who were excluded due to missing data with respect to 6MWD, which was a primary outcome of PR. However, as mentioned previously, this did not significantly affect survival results in the present study. Finally, it was not always possible to ascertain whether patients experienced a recent exacerbation. This could have been important because patients with a recent exacerbation may have been individuals with a higher potential mortality. Despite these limitations, this cohort was a good representation of the type of patients seen in clinical PR programs, thereby making the present study more clinically relevant.

\section{CONCLUSION}

Patients with severe COPD who have poor functional status as measured by 6MWD have a high potential mortality. Patients with the lowest exercise capacity and who are unable to achieve improvement may be those who have the very worst prognosis. Given the difficulty in projecting patient trajectory, measurement of 6MWD is useful as a predictive tool. In addition, the present study highlights the role of PR to better evaluate prognosis in a severely limited COPD patient population. This information can serve as a method to focus clinical interventions and perhaps in some cases, to bridge the gap between active treatment and symptom management.

ACKNOWLEDGEMENT: The authors thank Dr Chantal Robitaille for her invaluable comments regarding the manuscript.

FUNDING SOURCE: Mount Sinai Hospital Centre Research Fund.

\section{REFERENCES}

1. World Health Organization. Ten leading causes of death in the world, 2010-2012. Geneva: World Health Organization. <http://www.who.int/mediacentre/factsheets/fs310/en/> (Accessed August 4, 2014).

2. Hoyert DL, Xu J. Deaths: Preliminary Data for 2011. National Vital Statistics Report 2012. Natl Vital Stat Rep 2012;61:1-51. 
3. Global Strategy for the Diagnosis, Management and Prevention of COPD, Global Initiative for Chronic Obstructive Lung Disease (GOLD) 2010. <www.goldcopd.org/> (Accessed August 2014).

4. Celli BR. Predictors of mortality in COPD. Respir Med 2010;104:773-9.

5. Cote CG, Pinto-Plata VM, Marin JM, Nekach H, Dordelly LJ, Celli BR. The modified BODE index: Validation with mortality in COPD. Eur Respir J 2008;32:1269-74.

6. Martinez FJ, Foster, G, Curtis JL et al. Predictors of mortality in patients with emphysema and severe airflow obstruction. Am J Resp Crit Care 2006;173:1326-34.

7. Casanova C, Coté, C, Marin, JM, et al. Distance and oxygen desaturation during the 6 -min walk test as predictors of long-term mortality in patients with COPD. Chest 2008;134:746-52.

8. Salzman SH. The 6-Min Walk Test: Clinical and research role, technique, coding, and reimbursement. Chest 2009;135:1345-52.

9. Pinto-Plata VM, Coté, C, Cabral H, Taylor J, Celli BR. The 6-min walk distance: Change over time and value as a predictor of survival in severe COPD. Eur Respir J 2004;23:28-33.

10. Lisboa BC, Barria PP, Yanez VJ, Aguire ZM, Diaz PO. [Six minute walk for the assessment of patients with chronic obstructive pulmonary disease.] Rev Med Chil 2008;136:1056-64.

11. American Thoracic Society. ATS Statement: Guidelines for the Six-Minute Walk Test. Am J Crit Care Med 2002;166:111-7.

12. Zanini A, Chetta A, Gumiero F, et al. Six-minute walking distance improvement after pulmonary rehabilitation is associated with baseline lung function in complex COPD patients: A retrospetive study. BioMed Res Int 2013:1-6.

13. Polkey MI, Martijn A, Spruit LD, et al. Six-minute-walk test in chronic obstructive pulmonary disease: Minimally clinically important difference for death or hospitalization. Am J Resp Crit Care 2013;187:382-6.

14. World Health Organization. International Statistical Classification of Diseases and Related Health Problems 10th Revision. $<$ http://apps.who.int/classifications/icd10/browse/2010/en> (Accessed August 15, 2013).

15. Allison PD. Survival Analysis Using the SAS System. A Practical Guide, 2nd edn. Cary: SAS Institute, 2010.

16. Jager K, van Dyke PC, Zoccali C, Dekker FW. The analysis of survival data: The Kaplan-Meier method. Kidney Int 2008;74:560-5.
17. Butland RJ. Pang J, Gross ER, Woodcock AA, Geddes DM. Two-, six-, and 12-minute walking tests in respiratory disease. BMJ 1982;284:1607-8.

18. Kasymjanova G, Correa JA, Kreisman H, et al. Prognostic value of the $6 \mathrm{MWD}$ in advanced non-small cell lung cancer. J Thorac Oncol 2009;4:602-7.

19. Miyamoto S, Niagaya N, Satoh T, et al. Clinical correlates and prognostic significance of six-minute walk test in patients with primary pulmonary hypertension. Comparison with cardiopulmonary exercise testing. Am J Resp Crit Care 2000;161:487-92.

20. Caminati A, Bianchi A, Cassandro R, Mirenda MR, Harari S. Walking distance on 6-MWT is a prognostic factor in idiopathic pulmonary fibrosis. Respir Med 2009;103:117-23.

21. Waschki B, Kirsten A, Holz O, et al. Physical activity is the strongest predictor of all-cause mortality in patients with COPD. Chest 2011;140:331-42.

22. Enfield K, Gammon S, Floyd J, et al. Six-minute walk distance in patients with severe end-stage COPD: Association with survival after inpatient pulmonary rehabilitation. J Cardiopulm Rehabil Prev 2010;30:195-202.

23. Spruit MA, Polkey MI, Celli BR, et al. Predicting outcomes from 6-minute walk distance in chronic obstructive pulmonary disease. J Am Med Dir Assoc 2012;13:291-7.

24. Cote CG, Pinto-Plata V, Kasprzyk K, Dordelly LJ, Celli BR. The 6 min walk distance, peak oxygen uptake, and mortality in COPD. Chest 2007;132:1778-85

25. Provencio M, Isla D, Sánchez A, Cantos B. Inoperable stage III non-small cell lung cancer: Current treatment and role of vinorelbine. J Thorac Dis 2011;3:197-204.

26. Vokes EE. Optimal therapy for unresectable stage III non-small-cell lung cancer. J Clin Oncol 2005;23:5853-5.

27. Sequist LV, Joshi VA, Jãnne PA, et al. Response to treatment and survival of patients with non-small cell lung cancer undergoing somatic EGFR mutation testing. Oncologist 2007;12:90-8.

28. Brooks D, Sottana R, Bell B, et al. Characterization of pulmonary rehabilitation programs in Canada in 2005. Can Respir J 2007; 14:87-92. 


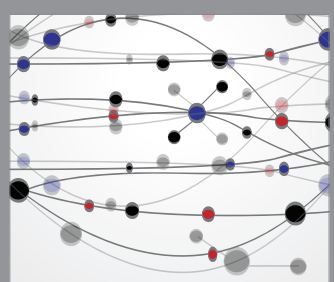

The Scientific World Journal
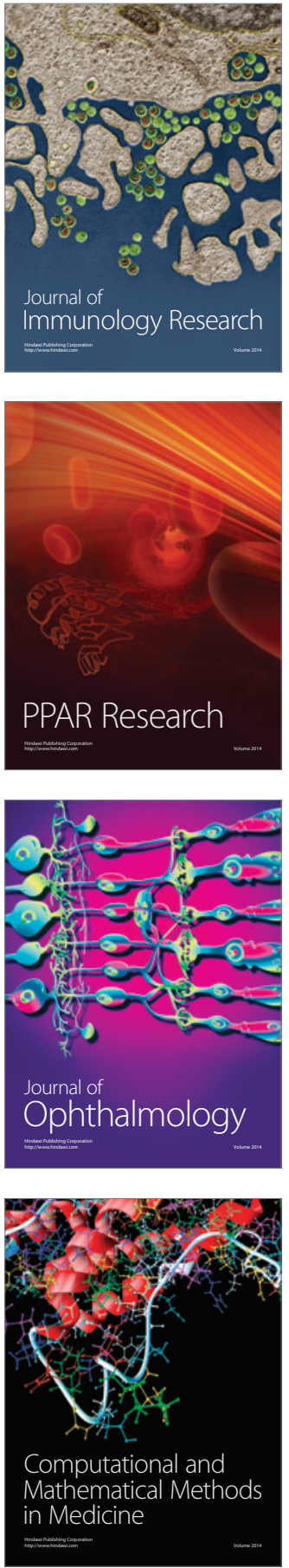

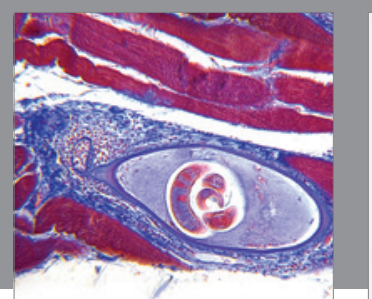

Gastroenterology Research and Practice

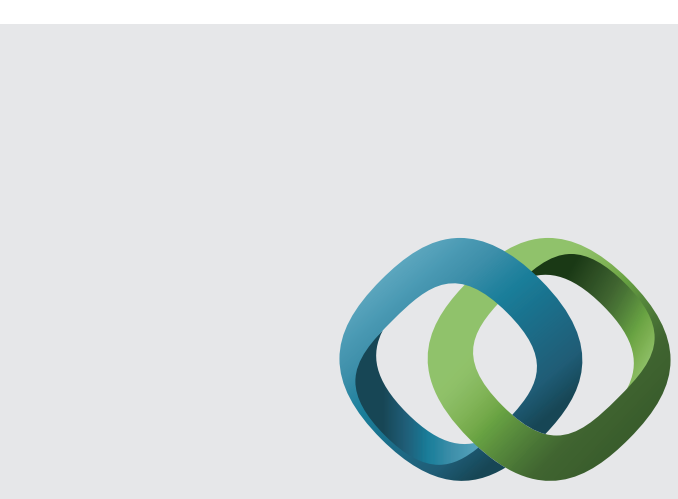

\section{Hindawi}

Submit your manuscripts at

http://www.hindawi.com
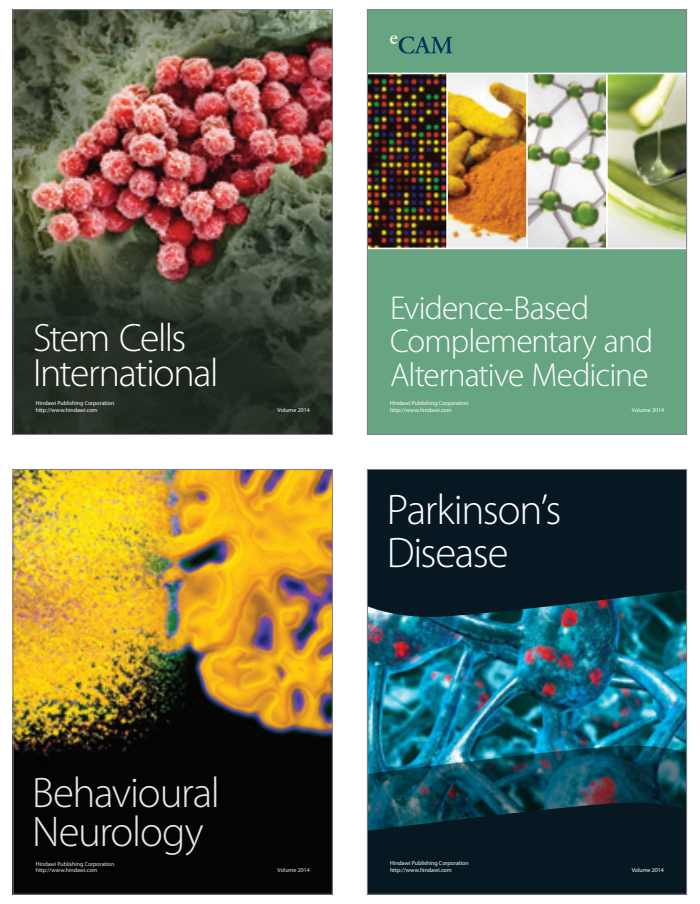
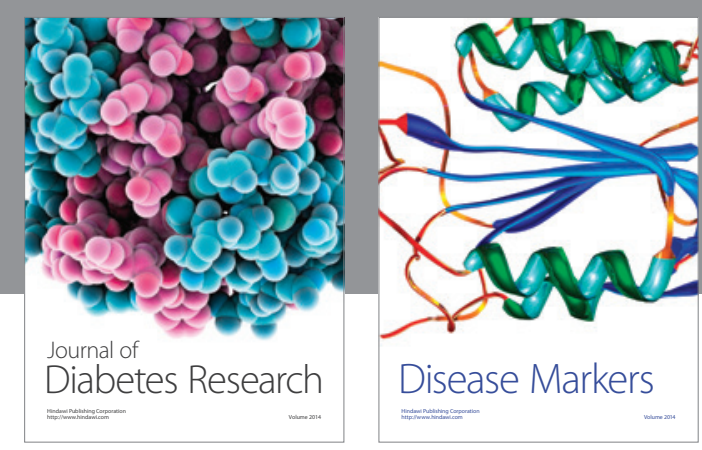

Disease Markers
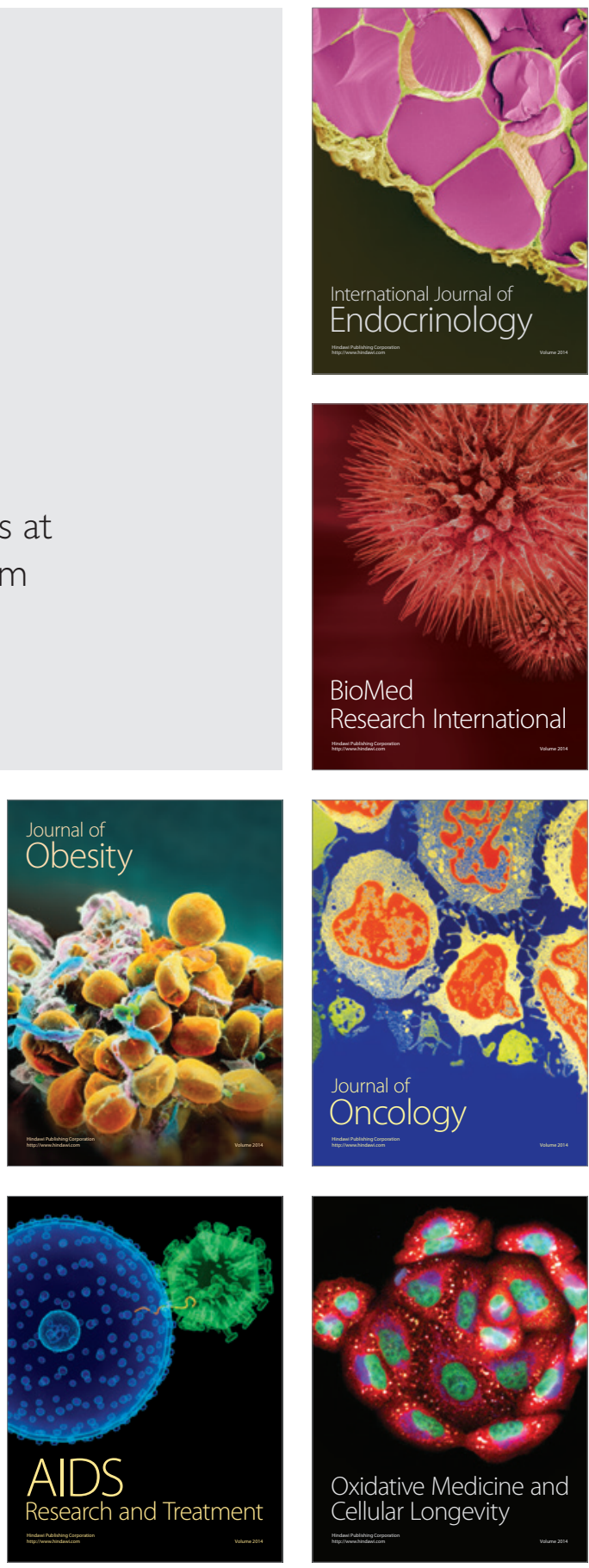